\title{
CUT THROAT INJURY- A CRITICAL EMERGENCY: REVIEW OF 47 CASES IN A TERTIARY CARE CENTRE IN EASTERN INDIA
}

MBBS, Post graduate trainee ENT and Head neck surgery (3rd year), R.G. Kar Medical College and Hospital

\section{Dr. Jayanta Saha*}

MBBS, MS(ENT), Associate Professor, Department of ENT, R.G Kar Medical College and Hospital *Corresponding Author

\section{Dr. Subhadeep Chowdhury}

MBBS, Post graduate trainee ENT and Head neck surgery (3rd year), R.G. Kar Medical College and Hospital

\section{ABSTRACT}

Objective: To determine causes behind cut throat injury, Analyses the demographics, evaluate treatment, complications, and outcome of cut throat injuries.

Methodology: This prospective observational type of study was conducted at a tertiary care hospital during June 2018 to December 2019. A total of 47 cases included in this study. The demographics were recorded, and evaluation of the patient was done as per ATLS protocol. Necessary investigations were performed, and management was done by a team comprised of anaesthetist, otolaryngologist, CTVS surgeon and psychiatrist. After discharge of the patients, follow up was done for 6 months

Results: In our study the M: F is 3.27:1 and 36-50 years age group were mostly affected. Most common cause of injury was suicidal (61.70\%). Majority patient had zone II injury (76.6\%). 68.09\% patients discharged within 8-14 days. Alteration of voice was most common complications $(14.9 \%) .61 .70 \%$ patients are living completely normal life without any morbidity. Mortality rate after admission was $8.51 \%$.

Conclusion: Cut throat injury is common in middle aged male and rural people. Suicidal injuries are most common cause behind it. Early planned interventions, multidisciplinary approach, and regular follow up can reduce the mortality and morbidity of the cut throat injury patient

\section{KEYWORDS}

Cut throat injury, suicidal, zone II, complications, outcome.

\section{INTRODUCTION}

Cut throat injuries are devastating, life threatening, and emergency condition dealt by ENT surgeons. These injuries cause physical as well as mental trauma, reduced quality of life and above all death. Globally, cut throat injuries account for approximately $5 \%$ to $10 \%$ of all traumatic injuries with multiple structures being injured in $30 \%$ of patients ${ }^{[1][2][3]}$. In developing countries, the incidence is increasing at a fast rate because of increasing conflict over limited resources, poor socioeconomic condition, unemployment, easy access to alcohol and increased crime rates ${ }^{[4]}$. According to Roon and Christensen's classification, neck injuries are divided into three anatomical zones. Zone I extends from sternal notch /clavicle to cricoid cartilage. Zone II extends from cricoid cartilage to angle of mandible and zone III extends from angle of mandible to base of skull. The aetiology of cut throat injuries can be broadly divided into suicidal, homicidal, and accidental $^{[5]}$. With a selective approach, severe active bleeding, hypovolaemic shock not responding to resuscitation, a rapidly expanding haematoma, a large blowing wound and major haemoptysis are indications for emergency surgery. The remaining patients are assessed clinically, and appropriate radiological and endoscopic investigations are undertaken if there is a suspicion of visceral injury ${ }^{[3]}$. The management of these injuries require a multidisciplinary approach with the close collaboration of the anaesthetist, otolaryngologist, CTVS surgeon and psychiatrist The anaesthetist secures an uncompromised airway and makes sure the patient is breathing; the otolaryngologist assesses the injury and repairs the severed tissues with the aim of restoration of swallowing, phonation and breathing, CTVS surgeon deals with repair of great vessels. The psychiatrist provides adequate mental care and supervision during and after surgical treatment ${ }^{[1],[5]}$

\section{AIMSAND OBJECTIVES}

1. To categorize the causes behind cut throat injuries

2. To analyse of the age, sex ratio, habitat, time of hospital arrival, objects involved in injury, site, and extent of injury

3. To evaluate the treatment of cut throat injuries, complications, and outcome after the management.

\section{MATERIALS AND METHODS}

This prospective observational type of study was conducted in the Department of Otorhinolaryngology and head neck surgery at a tertiary care centre. The study period was 18 months from June 2018 to December 2019.

Total 47 cases of cut throat wounds were included in this study irrespective of age and sex who were presented either directly to our department or from other peripheral centres. The consent was obtained from the patients except patients who presented drowsy or unconscious state and those who were under 18 years of age. In these cases, their parents, relatives had to consent on their behalf. Patients with head injury, polytrauma, patients who were brought dead, patients who did not give consent were excluded from this study.

Data was categorized according to age, sex, locality, mode of injury, causative agent of injury, site of injury, extent of the injury, treatment given, complications and the final outcome of the patient.

Patient with superficial cut throat injuries were managed by wound repair in layers with local anaesthesia at minor operation theatre. The patients with zone II injury involving the pharynx, larynx and trachea were transferred to the Trauma OT after resuscitated according to Advanced Trauma Life Support (ATLS) ${ }^{[6]}$.In such patients, emergency tracheostomy was done. During wound repair, first the wound was washed with normal saline thoroughly followed by povidone iodine and then the wound was repaired in layers. Ryle's tube was inserted in those cases where cut injuries extended to hypopharynx. Great vessels repair was done with help of CTVS surgeons. For mucous membrane, muscles and soft tissue of the neck, we used vicryl 2-0 and 3-0 suture material and for the cartilages of the larynx prolene 2-0. Skin was closed by 2-0 nylon after placing the corrugated rubber drain. Broad spectrum antibiotics were given to prevent infection. Regular dressings were done. The investigations during post op period were done to detect any complications or residual injuries, included X-ray chest PA view and CT scan neck. Haematological investigations were done to record complete blood count. Post op monitoring of laryngeal structures were done by using rigid 70-degree endoscope.

Sutures were usually removed after 7 days. After discharge of the patients, follow up were done for 6 months. Psychiatrist consultation was taken in all cases.

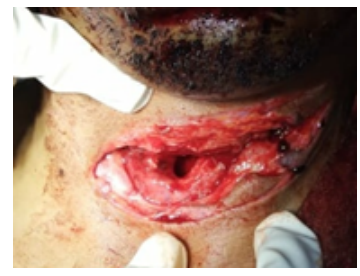

Fig 1: Homicidal cut throat injury 


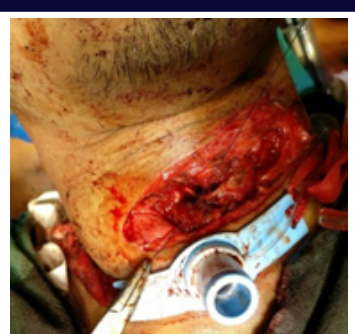

Fig 2: Tracheostomy has been done securing airway and wound is repaired in layers

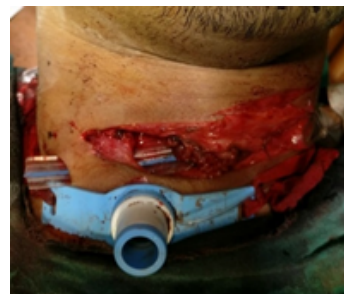

Fig 3: Corrugated rubber drain has been used before closing the skin

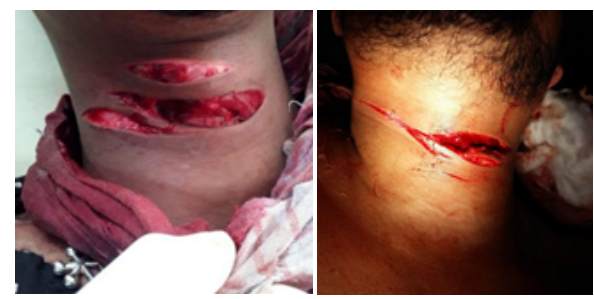

Fig 5 and 6 : Suicidal cut throat wounds with hesitation cuts

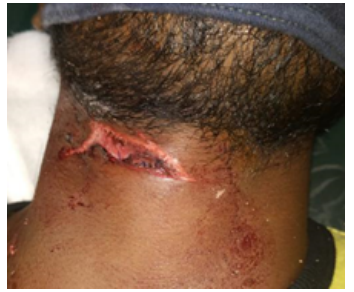

Fig 7: Accidental superficial cut throat injury due to fall on sharp metal object

\section{RESULTS:}

Among 47 patients we found that 36 patients are male (76.56\%) and 11 patients are female $(23.44 \%)$. (Fig 8$)$

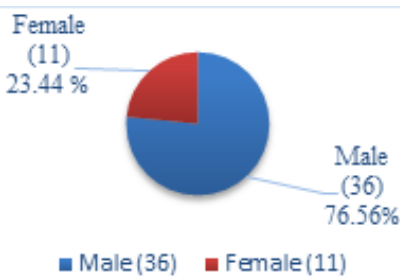

\section{Fig 8: Gender Distribution}

We found patients between 17 to 74 years, but majority of the patients were between $36-50$ years age group (44.68\%). (Fig 9)

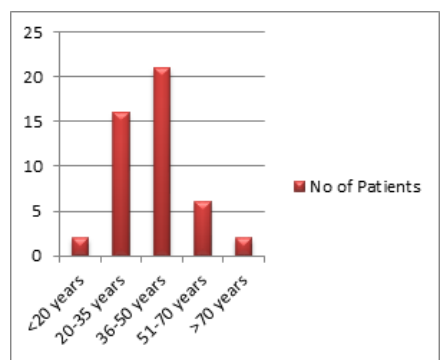

Fig 9 : Age Distribution
It is noted that rural people 28 out of $47(59.57 \%)$ are affected more than urban people.

It is seen in our study that 29 cut throat injuries were due to suicidal $(61.70 \%)$ followed by $12(25.53 \%)$ homicidal and $6(12.77 \%)$ accidental. Among the patients who attempted suicide 13 patients i.e. $37.93 \%$ are on psychiatry medications, among homicides personal vendetta or animosity is the most common cause followed by property dispute. (Table 1)

Table 1: Distribution of patients according to the causative factors or etiology of cut throat injury $(n=47)$

\begin{tabular}{|l|l|l|}
\hline Type of Injury & Causative factor & Frequency \\
\hline \multirow{4}{*}{$\begin{array}{l}\text { Suicidal } \\
\mathbf{n}=\mathbf{2 9}\end{array}$} & Psychiatric illness & $11(37.93 \%)$ \\
\cline { 2 - 3 } & Family problem & $8(27.59 \%)$ \\
\cline { 2 - 3 } & Love affairs & $5(17.24 \%)$ \\
\cline { 2 - 3 } & Drug abuse & $3(10.34 \%)$ \\
\cline { 2 - 3 } & Loss of employment & $2(6.9 \%)$ \\
\hline \multirow{3}{*}{$\begin{array}{l}\mathbf{n}=\mathbf{1 2} \\
\end{array}$} & Personal vendetta or animosity & $7(58.33 \%)$ \\
\cline { 2 - 3 } & Property dispute & $3(25 \%)$ \\
\cline { 2 - 3 } $\begin{array}{l}\text { Accidental } \\
\mathbf{n}=\mathbf{6}\end{array}$ & Love affairs & $2(16.67 \%)$ \\
\cline { 2 - 3 } & Road Traffic Accidents & $4(66.67 \%)$ \\
\hline
\end{tabular}

There were different objects involved in cut throat injury, most common being knife (27.66\%) followed by boti (19.15\%). (Fig 10)

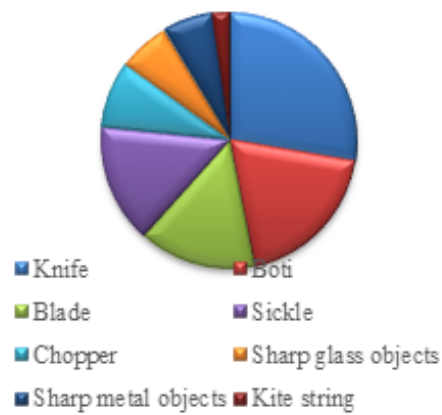

Fig 10: Various objects involved in cut throat injury

It is found that majorities of patients $63.82 \%$ presented with active haemorrhage and open wound. (Table 2)

Table 2: Distribution of patients according to presentation of injury

\begin{tabular}{|l|l|}
\hline Presentation of the injury & Frequency \\
\hline Active haemorrhage with open wounds & $30(63.82 \%)$ \\
\hline Stray suture and pressure bandage at neck & $7(14.89 \%)$ \\
\hline Severe respiratory distress & $6(12.77 \%)$ \\
\hline Haemorrhagic shock & $4(8.51 \%)$ \\
\hline
\end{tabular}

According to Anatomical Zones of the neck, most of the patients have Zone II injury (76.6\%) and most are suicidal $(66.7 \%)$ in origin. (Fig 11)

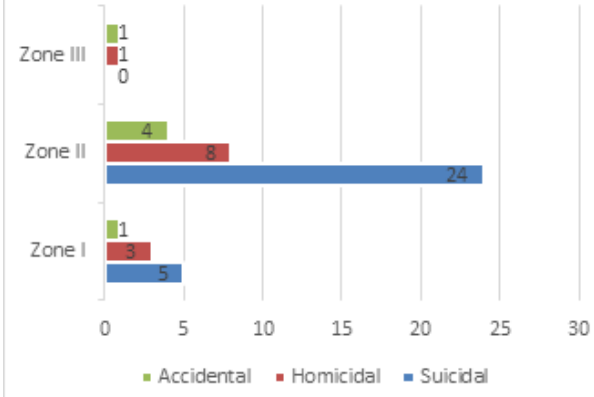

Fig 11: Distribution of patients according to anatomic sites (zone) of injury and etiology

Skin, superficial fascia, deep fascia breached in all the cases. Injuries to laryngeal cartilages were seen in 9 patients $(19.14 \%)$. Thyroid gland was injured in 3 patients $(6.38 \%)$. Injury extended to hypopharynx was 
noted among 8 patients (17.02\%). Internal jugular vein was injured in 3 patients $(6.38 \%)$ and we found only 1 case with carotid artery injury. Trachea was exposed and injured among 7 patients (14.89\%). (Table 3 )

Table 3: The distribution of structure injured and etiology

\begin{tabular}{|l|l|l|l|}
\hline Structure Injured & Homicidal & Suicidal & Accidental \\
\hline Laryngeal cartilages & $5(55.6 \%)$ & $1(11.1 \%)$ & $3(33.3 \%)$ \\
\hline Thyroid gland & $2(66.7 \%)$ & 0 & $1(33.3 \%)$ \\
\hline Hypopharynx & $4(50 \%)$ & $1(12.5 \%)$ & $3(37.5 \%)$ \\
\hline Trachea & $4(57.1 \%)$ & $1(14.3 \%)$ & $2(28.6 \%)$ \\
\hline IJV & $2(66.7 \%)$ & 0 & $1(33.3 \%)$ \\
\hline Carotid artery & $1(100 \%)$ & 0 & 0 \\
\hline
\end{tabular}

During the management, simple wound repair in layers and closure were done in 20 cases $(42.55 \%)$. Repair of larynx and hypopharynx with tracheostomy were done in 17 cases $(36.17 \%)$. Total 24 patient required tracheostomy. In 3 cases $(6.38 \%)$ ligation of internal jugular vein and repair of wound were done. Ryle's tube was inserted to all 8 patients whose hypopharynx were also injured, repaired in layers and kept in situ for at least 14 days. Blood transfusion was given to 15 patients $(31.91 \%)$. (Table 4). Psychiatric consultation was done in all cases to deal with mental trauma.

Table 4: Treatment provided in cut throat patients

\begin{tabular}{|l|l|}
\hline Treatment provided & $\begin{array}{l}\text { Number of patients with } \\
\text { percentage }\end{array}$ \\
\hline $\begin{array}{l}\text { Simple wound repair in layers and } \\
\text { closure }\end{array}$ & $20(42.55 \%)$ \\
\hline $\begin{array}{l}\text { Repair of larynx and hypopharynx with } \\
\text { tracheostomy }\end{array}$ & $17(36.17 \%)$ \\
\hline Repair of trachea with tracheostomy & $7(14.9 \%)$ \\
\hline $\begin{array}{l}\text { Ligation of internal jugular vein and } \\
\text { repair of wound }\end{array}$ & $3(6.38 \%)$ \\
\hline Ryle's tube insertion & $8(17.02 \%)$ \\
\hline Blood transfusion & $15(31.91 \%)$ \\
\hline
\end{tabular}

20 patients developed post-operative complications, most common being the alteration of voice (Fig 12)

4 patients died, 1 due to carotid artery blow out and 3 due to hypovolemic shock that developed due to delayed transport of the patient to our hospital.

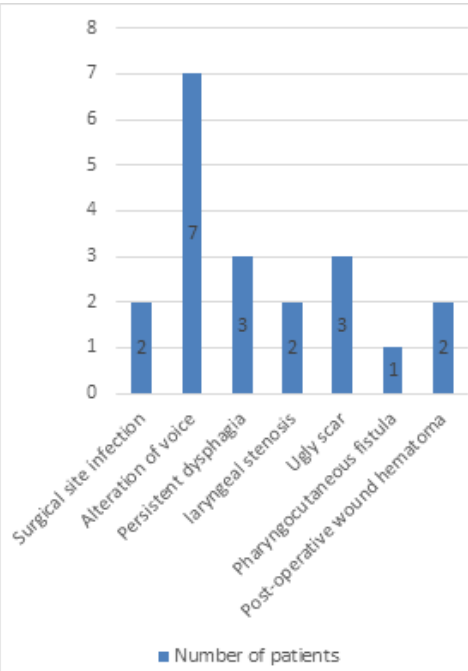

Fig 12: Distributions of patients with post op complications

Regarding hospital stay we found majority of the patients 32 out of 47 $(68.09 \%)$ were stayed in the hospital for $8-14$ days( Table 5)

Table 5: Average stay in hospital

\begin{tabular}{|l|l|}
\hline Average stay in hospital (days) & Number with percentage \\
\hline $3-7$ & $12(25.53 \%)$ \\
\hline $8-14$ & $32(68.09 \%)$ \\
\hline $15-21$ & $2(4.26 \%)$ \\
\hline$>21$ & $1(2.12 \%)$ \\
\hline
\end{tabular}

We found that 29 out of 47 patients are completely cured after treatment and rest are having some minor or major morbidity. (Table 6 )

Table 6: Outcome of patients

\begin{tabular}{|l|l|}
\hline Outcome & $\begin{array}{l}\text { Number of patients } \\
\text { with percentage }\end{array}$ \\
\hline Complete cured and living normal life & $29(61.70 \%)$ \\
\hline $\begin{array}{l}\text { Living with minor morbidity (alteration of } \\
\text { voice, ugly scar, persistent mild dysphagia) }\end{array}$ & $11(23.40 \%)$. \\
\hline $\begin{array}{l}\text { Living with major morbidity (Laryngeal } \\
\text { stenosis, pharyngocutaneous fistula) }\end{array}$ & $3(6.38 \%)$ \\
\hline Death & $4(8.51 \%)$ \\
\hline
\end{tabular}

\section{DISCUSSION:}

According to World Health Organization (WHO), every year over 5 million people around the world die as a result of an injury. As per WHO, it is estimated that for every death 10-20 gets hospitalized and 50-100 receives emergency care, indicating the enormous burden on the resources of the country ${ }^{[7]}$. It is a challenge to us to save the life of a cut throat injury patient. In this context, Amadasun highlighted problems of decision making in this critical condition of neck injury ${ }^{[8]}$. There is also an article on open neck injuries stressed on the surgical airway problems ${ }^{[9]}$.

In our study it is seen that male population affected (76.56\%) more than female. M: F ratio is 3.27:1. Similar type of findings are seen in Rautela et al. ${ }^{[10]}$. Male dominance is may be due to their active participation in risk taking behaviors, aggressiveness, and their frequent involvement in personal vendetta or animosity and drug abuse. Unemployment can also act as a stressful life event leading to suicide ${ }^{[11]}$. Majority of our study population is from rural area $(61.7 \%)$ as our tertiary care centre acts as a referral centre covering of large rural and suburban area and majority of urban people has propensity to attend different tertiary care centres in the city as well as other nongovernment institution. We found majority of the patients were between 36-50 years age group (44.68\%). This is in contrary to a study conducted by Rajesh Kumar Kundu et al. ${ }^{[12]}$ where they found $60 \%$ of the patients were between 16-30 years. The most common cause of injury in our study was suicidal followed by homicidal and accidental. This is in contradiction to the observation of Modi and Pandy ${ }^{[13]}$. They observed that suicidal cut throat injuries are rare in India. In contrast, suicidal cut throat injuries were the most common cause in the western population ${ }^{[14]}$. Similar finding was also reported in Bangladesh by Manilal et al ${ }^{[5]}$. While the link between suicide and mental disorders (in particular, depression and alcohol use disorders) is well established in high-income countries, but in a developing country like us suicides happen impulsively in moments of crisis with a breakdown in the ability to deal with life stresses, such as financial problems, relationship break-up, drug abuse or aggravated psychiatric illness due to irregular intake of psychiatric medications. We found knife is the most common object involved in cut throat injury. This is in contrary to study conducted by Dr. K. Santhaiah et al. where they found blade was the most common object ${ }^{[15]}$.

According to anatomical zone, most of the patients 36(76.6\%) patients had zone II injury. The predominance of Zone II injuries in our study is attributable to the fact that unlike Zones I and III, Zone II is not protected by bony structures making it more vulnerable to injuries ${ }^{[16]}$. Injuries in this zone are the easiest to expose in cut throat injury ${ }^{[1][]^{\circ}}$. Thus, in suicidal injury zone II is involved more.

Our study shows homicidal injury is more dangerous than suicidal and deeper structures injured more in homicidal injury which is like other studies ${ }^{[5]}$

Laryngeal cartilages are the most common deep structures (12.76\%) that injured in our study. No esophageal injury is seen in our study. 3 patients had injury to IJV and these were repaired with help of CTVS surgeons. We could not save one carotid artery injury patient due to massive blood loss before we could shift him to trauma OT. This finding is similar to finding with Rajesh Kumar Kundu et al. ${ }^{[12]}$

In this study, layered wound repair, laryngeal/hypopharynx repair and tracheostomy were the most common surgical procedures performed. Similar treatment patterns were reported by other authors ${ }^{[1][5][12]}$.

The benefit of tracheostomy in the management of cut throat injury has been highlighted in the literature ${ }^{[17]}$. It provides clear surgical field and 
prevents complications like air embolism and aspiration pneumonitis. It also reduces air way distress due to post opearative oedema. In our study $51.06 \%$ victims required tracheostomy. Among them decannulation was done in 22 patients and only 2 patients discharged with tracheostomy tube who had larynotracheal stenosis. This finding is similar to Rautela et al. ${ }^{[10]}$.

The presence of complications has an impact on the outcome of patients as supported by the present study. In contrary with other studies where majority of patients developed complications of which surgical site infections ${ }^{[5][18]}$, our study showed $14.9 \%$ complication was alteration of voice due to laryngeal trauma. Maintenance of proper asepsis and regular dressing decrease the surgical site infection rate in our hospital. The alteration of voice is due to injury to laryngeal cartilages and vocal cords and mostly seen in homicidal cut throats $(55.6 \%)$. Lacerated vocal fold were left alone and post-operative monitoring for granulation tissue formation with rigid 70-degree endoscope were done. 3 patients had ugly scar as there were skin and tissue losses and necrosis due to delayed arrival. Patients who did not follow the instruction of ryles tube feeding had developed persistent mild dysphagia. Counselling and close monitoring to them during post discharge subsequent OPD visits were done. Laryngotracheal stenosis has been seen in 2 patients. Both are due to lacerated injury resulted from road traffic accidents where anatomical integrity almost lost. So these were impossible to repair in proper anatomical and surgical layer. These modes of presentations are vulnerable. 1 patient developed pharyngocutaneous fistula who left the hospital against medical advice and returned to our OPD after 1 month with this complication. Improper care and oral feeding instead of ryles tube feeding was the cause behind it. Pharyngo-cutaneous fistula can be avoided by meticulous suturing of tissue layers, re-enforcing each other, avoiding overlapping of suture lines and choosing correct suture material. They can be prevented by Ryle's tube feeding and avoiding oral feeds, in the postoperative period ${ }^{[19]}$. The length of hospital stay is an important measure of morbidity among trauma patients. As prolonged hospitalization is associated with an unacceptable burden on resources for health and undermines the productive capacity of the population through time lost during hospitalization and disability ${ }^{[5][]}$. In our study majority $68.09 \%$ patients discharged within $8-14$ days. This finding is similar to other studies ${ }^{[5] 12]}$. During assessment of final clinical outcome, it is found that 29 patients $(61.7 \%)$ completely cured, living normal life which is better than the study conducted by Rajesh Kumar Kundu et al ${ }^{[16]}$. This implies adequate wound toileting and proper repair of wound in early admission, use of I.V broad spectrum antibiotics, close monitoring for any undetected vascular or aerodigestive tract injury, post op CT scans in selected cases, ryles tube feeding in hypopharyngeal injuries, strapping of tracheostomy tube after 10 days and checking airway patency helped in early recovery of the patient. Death rates after admission was $8.51 \%$ which is almost like study conducted by Manilal et al. and higher than the rate quoted by Rajesh Kumar Kundu et al (5\%) and Onotai et al ${ }^{[20]}$. and lower than the study conducted by Debdulal Chakraborty et al. (13.63\%) and Gilyoma et al $(11.2 \%)^{[18] .}$

\section{CONCLUSION:}

Cut throat injuries are very dangerous and can be fatal at times. Suicidal cut throat injury is most common etiology in our study. Middle aged male rural people are commonly affected. According to our study it is seen that proper planning with prompt actions and multidisciplinary approach can save majority of life with lowering the mortality and morbidities.

\section{Source Of Support: nil \\ Conflict Of Interest: none}

\section{REFERENCES}

1. Bhattacharjee N, Arefin SM, Mazumder SM, Khan MK (1997): Cut throat injury: a retrospective study of 26 cases. Bangladesh Med Res Counc Bull 23:87-90

2. Peden M, McGee K, Sharma G. The Injury Chart Book (2002): A Graphical Overview of the Global Burden of Injuries. World Health Organization, Geneva

3. Fagan J J, Nicol A J. Neck trauma. In, Gleeson M (ed) (2008). Scott - Brown's Otorhinolaryngology, Head and Neck surgery, 7th edition. Great Britain, Hodder Arnold. pp1768-69.

4. Kobusingye OC (2008): Violence and injuries: what Africa should do? Afr Health Monit 1:37-4

5. Manilal A, Khorshed ABM, Talukder DC, Sarder RMA, Fakir AT, Hossain M (2011): Cut throat injury: review of 67 cases. Bangladesh J Otorhinolaryngol 17:5-13

6. Rao BK, Singh VK, Ray S, Mehra M (2004): Airway management in trauma. Indian J Crit Care Med 8:98-105

7. Krug EG, Sharma GK, Lozano R (2000): The global burden of injuries, American Journal of Public Health 90:523-6

8. Amadasun JEO(1999): Decision making in self inflicted life threatening neck injuries report of two cases. J Oto-Rhino-Laryngol Head-Neck Surg 2:2-23

9. Eshiet Akpan, Antiaue SG, Onoym IV and Edentekhe TA (1979): Surgical airway problems and their management. The University of Calaban Teaching Hospital experience. Niger Postg Med J 4:15-8

10. Neha Rautela, Veerendra Verma, Shahab ali Usmani, Anupam Mishra, H.P. Singh, Sunil Kumar. Cut Throat Injuries(2017): The Socio-Demographic Pattern, Causes, and Outcome at Tertiary Care Hospital of North India. International Journal of Contemporary Medical Research, Vol 4, pp 136-140.

11. Shah A, Bhandarkar R(2008): Cross-national study of the correlation of general population suicide rates with unemployment rates. Psychol Rep 103:793-796

12. Rajesh Kumar Kundu, Bivas Adhikary, Sukanya Naskar(2013): A Clinical Study Of Management And Outcome Of 60 Cut Throat Injuries. Journal of Evolution of Medical and Dental Sciences Vol2, pp 9444-9452

13. Modi JP, Pandy AS In: Modi NJ (ed) (1977): Modis medical jurisprudence and toxicology, 20th edn. Lexisnexis Buerworths Wadhwa, Bombay, India, pp 256-275.

14. Simpson CK In (1991): Knight B (ed) Simpsons forensic medicine, 10th edn. Eward Arnold, Hodder and Stoughton Ltd.,London, pp 101-102

15. Dr. K. Santhaiah, Dr. Muthireddy Sobha Rani, Dr. P. V. Sampath Kumar (2019): A Study Of Increasing Incidence Of Cut Throat Injuries And Their Management, Indian Journal Of Applied Research. Vol 9, pp14-15.

16. Debdulal Chakraborty, Chiranjib Das,Arvind Kumar Verma,Rajesh Hansda (2017): Cut Throat Injury: Our Experience in Rural Set-Up. Indian J Otolaryngol Head Neck Surg 69(1):35-41

17. Ezeanolue $\mathrm{BC}(2007)$ : Management of the upper airway in severe cut throat injuries. Afr JMed Med Sci 30:233-235

18. Gilyoma et al. (2014): Cut throat injuries at a university teaching hospital in northwestern Tanzania: a review of 98 cases. BMC Emergency Medicine 14:1

19. Ahmed MA, Rao MS, Ahmed SM, Kumar MM (2015): Cut throat injuries and it management: a clinical study of 48 patients. J Evol Med Dent Sci 4(38):6572-6581,

20. Onotai LO, Ibekwe U(2010). The pattern of cut throat injuries in the University of PortHarcourt Teaching Hospital, Portharcourt. Niger J Med. 19(3):264-266 